\title{
Influence of Nanoscaled Surface Modification on the Reaction of A1/Ni Multilayers
}

\author{
Heike Bartsch 1,* (D) José Manuel Mánuel ${ }^{2,3}$ (D) and Rolf Grieseler ${ }^{1,4}$ \\ 1 Institute of Micro- and Nanotechnologies, Technische Universität Ilmenau, 98693 Ilmenau, Germany; \\ rolf.grieseler@tu-ilmenau.de \\ 2 Facultad de Ciencias, Universidad de Cádiz, 11510 Puerto Real, Spain; jose.manuel@uca.es \\ 3 Institute of Research on Electron Microscopy and Materials, Universidad de Cádiz, 11002 Cádiz, Spain \\ 4 Physics Department, Pontificia Universidad Católica del Perú, San Miguel, 15088 Lima, Peru \\ * Correspondence: heike.bartsch@tu-ilmenau.de; Tel.: +49-3677-69-3452
}

Received: 9 November 2017; Accepted: 4 December 2017; Published: 7 December 2017

\begin{abstract}
Sputtered reactive multilayers applied as a heat source in electronic joining processes are an emerging technology. Their use promises low-stress assembly of components while improving thermal contact and reducing thermal resistance. Nanostructured surface modifications can significantly enhance adhesion and reliability of joints between different materials. This work examines reactive multilayer of nickel and aluminum, directly sputtered on nanostructured black silicon surfaces and compares their phase transformation with reference samples deposited on pristine silicon surface. The investigation of the quenched self-propagating reaction reveals a clear influence of the nanostructured surface on the prolongation of the phase transition. Rapid thermal annealing tests result in the formation of $\mathrm{Al}_{1.1} \mathrm{Ni}_{0.9}$ phase. The nanostructured interface seems to hinder the full transformation of the parent material. The surface modification improves the adhesion of the formed alloy on silicon surfaces and can possibly increase the reliability of joints based on reactive aluminum/nickel multilayer. The use of black silicon, a nanostructured surface modification, is thus a promising approach to realize reliable multi-material joints in complex systems.
\end{abstract}

Keywords: reactive multilayer; sputtering; self-propagating reaction; aluminum/nickel; black silicon; joining technology; nanostructured silicon; reactive nanomaterial

\section{Introduction}

Today's electronic systems must provide increased performance whilst reducing size at the same time. This pushes the development of effective and cost-efficient methods of heat removal [1]. Overall thermal challenges encompass hot spot thermal management on packaging level and heat spreading from chips to heat sinks [2]. This entails enhanced requirements on thermal interface materials [3]. The direct mount of chips on heat sinks, strongly driven by packaging requirements of LED chips, enters the field of integrated circuit and microelectromechanical systems (MEMS) packaging. However, the assembly of complex dies with numerous contacts and fine pitch creates high demands and the huge mismatch of thermal expansion between silicon and heat sink must be compensated in order to minimize stress.

One solution for stress minimization is the use of local heat exposure during the bond process [4]. Self-propagating exothermic reactions of multilayer films can be used to generate a local heat source and melt a solder between silicon chips and a board or heat sink. The reaction is driven by a reduction in atomic binding energy. The mechanism is observed when multilayer films of bimetal layers with a single layer thickness between $10 \mathrm{~nm}$ and $150 \mathrm{~nm}$ - such as $\mathrm{Ni} / \mathrm{Si}, \mathrm{Al} / \mathrm{Ti}, \mathrm{Al} / \mathrm{Ni}$, or $\mathrm{Al} / \mathrm{Pd}$-are ignited with an energy pulse, e.g., an electric spark or a laser pulse. 
Several works dwell on the use of such reactive multilayers (RML) for chip joining. One approach uses aluminum nickel nanofoils in combination with indium solder. A thermal interface with improved performance in comparison with a polymeric-based interface is created at room temperature. Due to a very restricted heating zone, the thermal stress is minimized and a tight bond is achieved [5]. The direct deposition of reactive layers on components expands the material variety and allows improved stress control. Sputtered Ti/Si and $\mathrm{Al} / \mathrm{Pd}$ multilayers form bond interfaces using Sn solder for the assembly of silicon MEMS at room temperature [6]. These integrated RML allow the direct and hermetic bond between two silicon chips and between silicon and ceramic, and glass and metal as well [7]. Al/Ni integrated RML, directly deposited on low temperature cofired ceramics (LTCC) can be used for the joining of copper heat sinks. The higher roughness of the ceramic substrate leads to a better adhesion in comparison with pristine wafer surfaces [8]. Al/Ni RML stand out through a very fast exothermic propagation, easy preparation, and easy ignition. However, stress control is an ongoing topic using these materials in order to avoid cracks and voids which reduces thermal performance [9]. Besides thermal performance increase, improved mechanical compliance is an ongoing target in the development of thermal interface materials (TIMs). A metallic interlayer can be used to increase the strength, because the type of interlayer influences the fracture origin [10]. Another approach to stress reduction is the use of nanostructured interfaces. Nanothermal interfaces can reach very low thermal resistance, undercutting values of $1 \mathrm{~W} / \mathrm{m}^{-1} \mathrm{~K}^{-1}$ [11]. An enhancement of the bonding strength can be achieved by surface modifications of silicon in the nanoscale. Surface enlargement and additional form fit affect adhesive bond strength and ductility of the interface [12,13]. Plasma etching of the silicon surface generates nanostructures by self-masking, the so-called black silicon [14]. The cost-effective process can be easily applied on any silicon surface in plasma processes used for mesa-structure etching of chips. If this surface modification entails a stress reduction in combination with RML chip assembly, the chip would be optimally prepared and additional process steps such as sputtering of intermediate layers can be omitted. With this motivation, the present work aims to provide the first insight into the interplay between surface morphology and reaction behavior of $\mathrm{Al} / \mathrm{Ni} \mathrm{RML}$. A comparison between pristine silicon wafer surface and black silicon modified silicon wafer surface, sputtered with aluminum/nickel as parent multilayer, is the base of the discussion-focusing on parent multilayer growth, reactive multilayer thickness, and their influences on phase forming and reaction propagation. On this base, a scenario for possible applications of RML on black silicon as nanothermal interface for chip mounting is outlined.

\section{Materials and Methods}

Black silicon is formed as a consequence of self-organized micromasking in fluorine based reactive ion etch processes of silicon wafers [14]. The geometry of the needles depends on the etch process [15]. In this work, nanostructure etching is performed in an Oxford RIE reactor with a pressure of $100 \mathrm{mTorr}$, working at a power of $100 \mathrm{~W}$ and $20{ }^{\circ} \mathrm{C}$ with helium backing, using a gas flow of $84 \mathrm{sccm} \mathrm{SF}_{6}$, and $66 \mathrm{sccm} \mathrm{O}_{2}$. P-doped (111) silicon wafers are used as the substrate. The process was maintained for $30 \mathrm{~min}$, resulting in needles of approximately $1.0 \mu \mathrm{m}$ of length. A pristine, flat wafer without nanostructures is used for comparison purpose. On both substrate types, the nanostructured silicon wafer and the flat ones, aluminum/nickel RML are directly applied. The layer consists of alternating nanoscaled single layers of pure aluminum and nickel which were deposited by magnetron sputtering. The bilayer thickness amounts to $50 \mathrm{~nm}$. The process was carried out using a cluster system (CS400 by ARDENNE) with a sputtering power of $200 \mathrm{~W}$ and a working pressure of $5 \times 10^{-3} \mathrm{mbar}$ with $80 \mathrm{sccm}$ argon flow and without substrate heating. The obtained deposition rate was $0.32 \mathrm{~nm} / \mathrm{s}$ for aluminum and $0.26 \mathrm{~nm} / \mathrm{s}$ for nickel. The total thickness of the multilayer sequence varies between $250 \mathrm{~nm}$ and $5 \mu \mathrm{m}$. The experimental design is summarized in Table 1 . 
Table 1. Overview on samples and experimental design.

\begin{tabular}{cccccc}
\hline No. & Substrate & $\begin{array}{c}\text { Bilayer } \\
\text { Thickness }(\mathbf{n m})\end{array}$ & $\begin{array}{c}\text { Total RML } \\
\text { Thickness }(\mathbf{n m})\end{array}$ & RTA T $_{\text {max }}\left({ }^{\circ} \mathbf{C}\right)$ & $\begin{array}{c}\text { Spark Ignition } \\
(\mathbf{V}) /(\mathbf{m A})\end{array}$ \\
\hline 1 & Flat wafer & 50 & 1000 & $350 / 450 / 550$ & - \\
2 & Flat wafer & 50 & 5000 & $350 / 450 / 550$ & $50 / 50$ \\
3 & Black silicon & 50 & 500 & $350 / 450 / 550$ & $50 / 50$ \\
4 & Black silicon & 50 & 1000 & $350 / 450 / 550$ & $50 / 50$ \\
5 & Black silicon & 50 & 5000 & $350 / 450 / 550$ & $50 / 50$ \\
\hline
\end{tabular}

The prepared wafers are mechanically carved along the substrate's main crystallographic directions using a diamond tip and broken in samples with an edge length between 1 and $2 \mathrm{~cm}$. One piece of each wafer was stored for reference, one was ignited by electric spark, and three pieces were annealed at different temperatures. The layer morphology on the nanostructures was investigated by SEM (Field-Effect ZEISS Gemini SEM 500 working at $1.5 \mathrm{kV}$ and working distance of $8 \mathrm{~mm}$, Carl Zeiss Microscopy GmbH, Jena, Germany) and TEM (TECNAI S20 working at $200 \mathrm{kV}$, FEI, Eindhoven, Netherlands). SEM micrographs were obtained by positioning the broken pieces of the samples, without further preparation, in a planar or a transversal disposition regarding to the electron beam. TEM preparation consisted of scratching the nanostructured and coated surface of the samples with a surgical blade, in order to separate the needles from the silicon substrate. The separated needles were deposited on holey carbon grids without further preparation for TEM measurements. The images of SEM and TEM analysis are depicted in Figure 1. Self-propagating reactions were initiated on one sample of each wafer. An electric spark was formed between a platinum electrode and the coated surface, applying a voltage of $50 \mathrm{~V}$ and a maximum current of $50 \mathrm{~mA}$ with a lab power supply. Fifty ignition points were generated, and their dimensions were investigated with a light microscope in order to assess the influenced region dependent on multilayer thickness on an adequate confidence level. The influenced region can be identified by a color change with a light microscope. The affected area of the nanostructured samples and the $5 \mu \mathrm{m}$ thick flat sample were investigated with a light microscope (Nikon Eclipse LV100POL, Nikon GmbH, Essen, Germany) and the radius of the affected spots was measured with the microscopes image processing software (NIS Elements Imaging Software 4.30.00, Nikon). The discolored area is enclosed with a circle, defined on three points on the circumference, the software calculates the affected radius $r_{\text {aff }}$ and the values are summarized in an Excel sheet. The box plots in Figure 2a display median and quantiles of the respective value distribution on nanostructured samples. The morphology of the affected zone was investigated by SEM. Fused areas were subsequently colored in purple to achieve a better visibility. Selected pictures are depicted in Figure 2b-e.

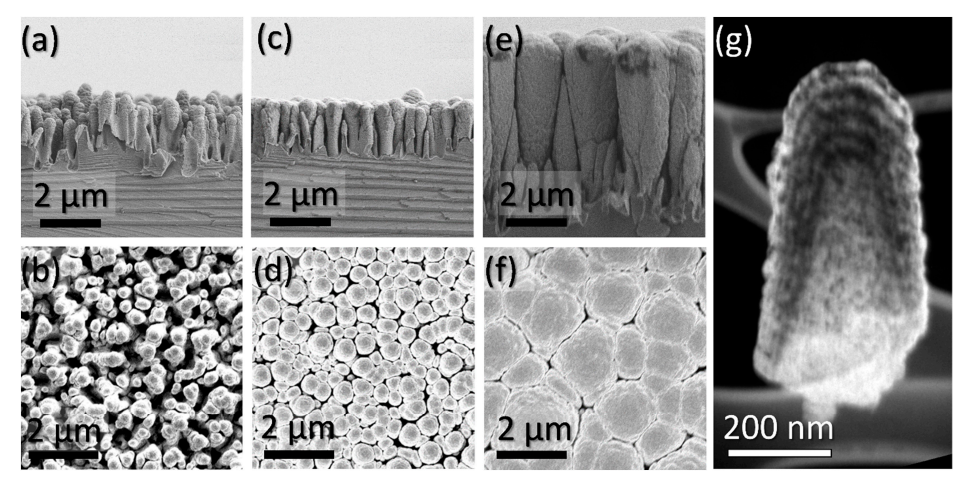

Figure 1. SEM micrographs of multilayers with different thickness, grown on black silicon nanostructures: (a,c,e) cross section of multilayers with $500 \mathrm{~nm}, 1 \mu \mathrm{m}$, and $5 \mu \mathrm{m}$ thickness; $(\mathbf{b}, \mathbf{d}, \mathbf{f})$ top view on the respective layer; (g) dark field TEM image of a nanostructure tip with $20 \mathrm{~nm}$ radius, coated with a $250-$ nm-thick multilayer. 

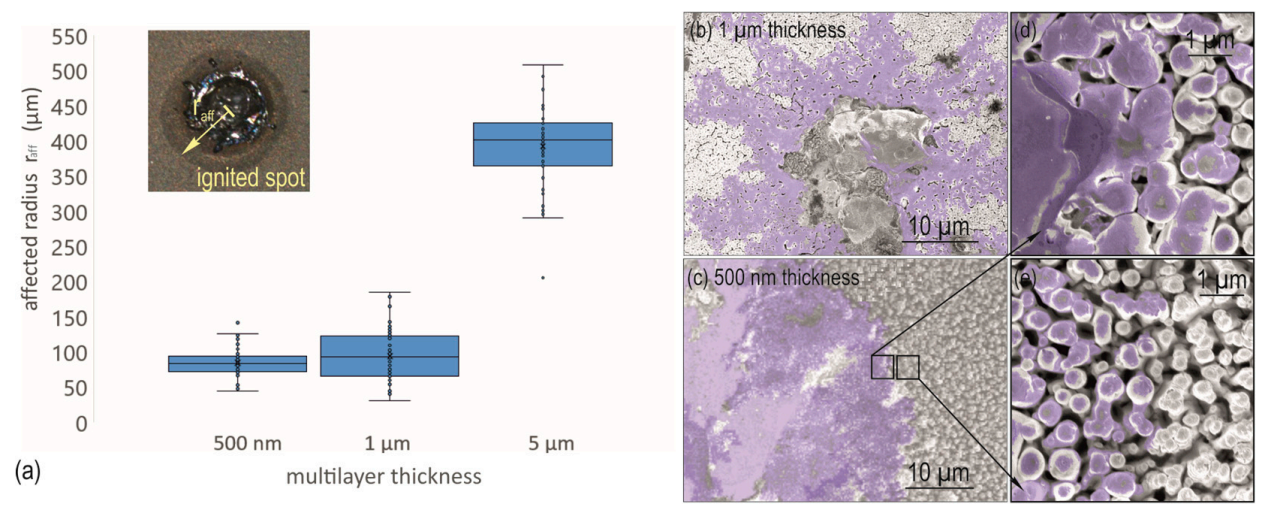

Figure 2. Affected zone dependent on layer thickness on nanostructured surface. (a) box plot of the affected radius measured by light microscope as function of layer thickness; (b) false color SEM image of ignition zone; zone is minimal larger and has dendrite shape, form is irregular, fractal distribution of the ignition over nanostructures on top, molten areas are colored; (c) false color SEM image of $500 \mathrm{~nm}$ layer. Ignited zone has a round shape, molten area ends abruptly; (d) detail of the border area, molten layers on top are depicted in false color; (e) outermost area of influenced zone, some tips show fused structure (false color).

Furthermore, samples of each wafer were annealed in a rapid thermal furnace (Jet First, Joint Industrial Processor for Electronics) under argon atmosphere (RTA). The maximum temperature $\mathrm{T}_{\max }$ was varied between $350{ }^{\circ} \mathrm{C}$ and $550{ }^{\circ} \mathrm{C}$. Figure 3a illustrates temperature treatment and gas flow regime. Figure $3 \mathrm{~b}$ gives a schematic of the reactor setup. Treated and untreated samples were investigated with a laser scanning microscope (LSM, Olympus OLS4100, Olympus Europa SE \& Co., KG, Hamburg, Germany), selected surface pictures and a height profile are compared in Figure 4. The treated samples were investigated with XRD (Bruker D5000 diffractometer with Göbel mirror, working in Bragg-Brentano mode at a speed of $0.1 \mathrm{~s}$ per step, using sampling steps of $0.04^{\circ}$ without sample rotation, Bruker AXS Analytical X-Ray Systems GmbH, Karlsruhe, Germany) to identify formed phase and grade of phase formation. Diffractograms were recorded over the $20^{\circ}<2 \theta<100^{\circ}$ range. Phase identification was performed by analyzing the positions and intensities of the peaks observed in the diffractograms and comparing them with data bases patterns. Extracts between $20^{\circ}$ and $65^{\circ}$ are depicted in Figure 5. Energy dispersive X-ray spectroscopy (EDX) is carried out at $20 \mathrm{kV}$ acceleration voltage (EDAX detector with super ultra-thin window of $30 \mathrm{~mm}^{2}$ area, nitrogen cooled, AMETEK GmbH, Weiterstadt, Germany) in order to determine the chemical composition.
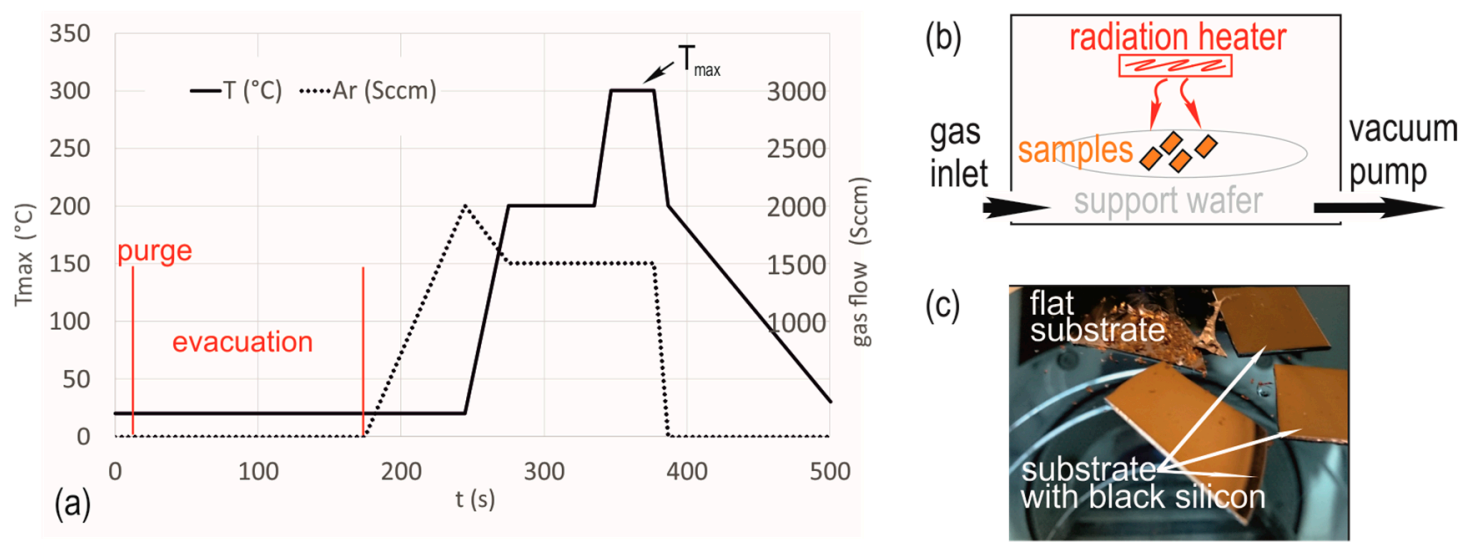

Figure 3. Rapid thermal annealing (RTA) process. (a) Temperature profile with gas flow regime, $\mathrm{T}_{\text {max }}$ varies between $350{ }^{\circ} \mathrm{C}$ and $550{ }^{\circ} \mathrm{C}$, the heat-up time is $12 \mathrm{~s}$ and plateau time $30 \mathrm{~s}$; (b) schematic of RTA set-up; (c) photograph of treated samples on support wafer. 


\section{Results}

\subsection{Parent Multilayer Morphology on Nanostructures}

The parent bilayer layer consists of alternating sequences of fcc $\mathrm{Ni}$ and fcc Al, identified by comparison of the XRD diffractograms with PDF 03-065-2865 and PDF 03-065-2869. EDX analysis reveals a composition of 50 at \% Ni: 50 at \% Al with a deviation of 3\%. The cross sections in Figure 1a,c,e illustrate that the edge coverage of the sputtered layers on black silicon is not uniform. A progressive growth of larger clusters at the structure's top occurs at the expense of smaller clusters. With increasing thickness, the gaps between single nanostructures are filled from the top of the substrate. While single structures covered with a 500-nm-thick multilayer still are separated, some touch at the top when the layer is $1 \mu \mathrm{m}$ thick. The black silicon structures covered with a 5 - $\mu \mathrm{m}$-thick layer have direct contact on top, visible in the top view Figure $1 b, d$,f. However, the cross sections indicate that hollows are present at deeper levels. The TEM image in Figure $1 \mathrm{~g}$ reveals that the deposition rate at the nanostructure's foot is much lower than on top, resulting in a steady decrease of the bilayer thickness. At a depth of approx. $500 \mathrm{~nm}$ from the top of the structure, the bilayer thickness is only $1 / 4$ of the one on the structure top. In all probability, the intermixed layer formed during sputtering and pure metal layers reaches similar thickness at the structure foot, resulting in disruption of the crystal structure, grain boundary structure, and lattice structure in this region.

\subsection{Spark Ignition}

Molten ares are visible on all samples around the ignition point. This molten zone is surrounded with a ring, which can be recognized by a color change under the ligth microscope. The border of this region marks the end of the affected material and is used to asses the affected zone by spark ignition. The box plot of the affected zones radius $r_{\text {aff }}$, measured on black silicon for different $\mathrm{Al} / \mathrm{Ni}$ multilayer thickness, is depicted in Figure 2a. The values follow a Gaussian distribution. The dependency of the median values of $r_{\text {aff }}$ on layer thickness can be approximated by a quadratic polynom with high accuracy. Median values correspond to $84 \mu \mathrm{m}$ for $500 \mathrm{~nm} \mathrm{Al} / \mathrm{Ni}$ multilayer thickness, $92 \mu \mathrm{m}$ for $1 \mu \mathrm{m}$ and $391 \mu \mathrm{m}$ for $5 \mu \mathrm{m}$. The comparison between $r_{\text {aff }}$ of the 5 - $\mu \mathrm{m}$-thick flat sample, which amounts to $468 \mu \mathrm{m}$, and this of the nanostrutured interface with equal RML thickness shows that black silicon surface modification narrows down the affected zone. $\mathrm{R}_{\mathrm{aff}}$ is reduced to 80 percent. The shape of the affected area on black silicon is depicted in Figure $2 b, c$. The influenced zone of $5 \mu$ m-thick-layer (not depicted) and $500 \mathrm{~nm}$ thick layers are characterized by a round contour. The transition ring area between molten material and unaffected structures has a width of $100 \mu \mathrm{m}$ for 5 - $\mu \mathrm{m}$-thick layers. In the case of 500-nm-thick layers, it is restricted to approximately $10 \mu \mathrm{m}$. Details of this transition area are depicted in Figure 2d,e. While the structures in the near vicinity still show closed molten links to the spark area, those next to them are characterized by a changed morphology, but not linked with adjacent ones. Ignited regions on samples with 1- $\mu$ m-thick $\mathrm{Al} / \mathrm{Ni}$ multilayers are characterized by a dendrite shape of the molten areas. The reaction propagates along paths were the tips of the nanostructures have contact and peter out. The affected area identified by light microscope has mostly circular, and in some cases eliptical contours.

\subsection{Rapid Thermal Annealing}

The RTA process uses heat radiation to initiate the phase transformation, which is here driven by solid diffusion. Layers on flat silicon surfaces (compare Figure 4a) flake during the treatment, independently from thickness and maximum temperature. An example is depicted in Figure 4b-e. A remarkable orientation of chipped traces is visible in Figure $4 \mathrm{~b}$. The peel-off seems to follow the single-crystal structure of the silicon substrate. Trapezoidal flakes are formed as depicted in Figure 4c. These exhibit strong tensile stress, which can be concluded from the strong bend visible in Figure 4e. Layers on black silicon showed excellent adhesion without exception. Photographs of samples with $1 \mu \mathrm{m}$ coating before and after treatment at $450{ }^{\circ} \mathrm{C}$ are depicted in Figure $4 \mathrm{f}, \mathrm{g}$. Surface images captured 
with LSM are depicted in Figure $4 \mathrm{~h}, \mathrm{i}$. The phase transformation can optically be identified by the color change. Neither the LSM top view, Figure 4i, nor the cross-sectional SEM image, Figure 4j, exhibit signs of molten material.

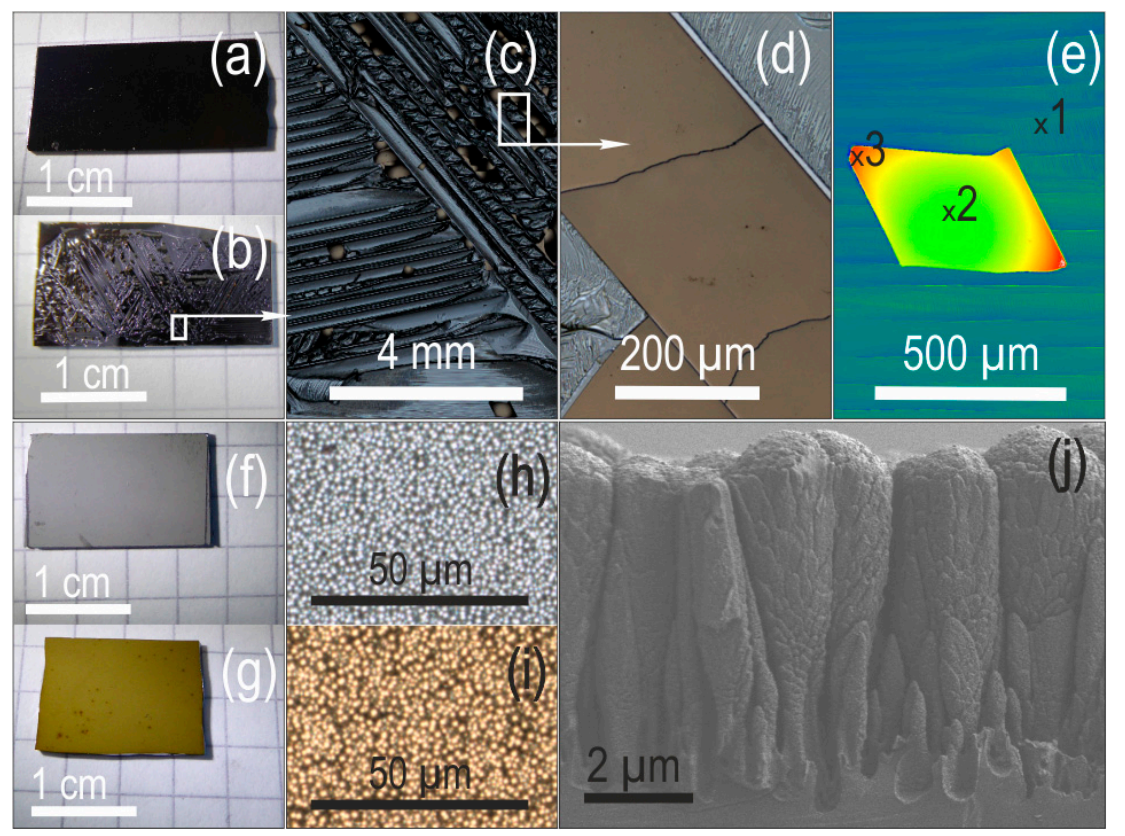

Figure 4. Comparison of RTA test samples before and after treatment at $450{ }^{\circ} \mathrm{C}$. (a-e) flat silicon chip; (a) before treatment; (b) after treatment; (c) LSM image of the surface after treatment; (d) LSM image of a transformed area; (e) height map of an adhered flake. Height level at point $1=0 \mu \mathrm{m}$, point $2=28 \mu \mathrm{m}$, point $3=50 \mu \mathrm{m}$. (f-j) chips with black silicon; (f) chip with $1 \mu \mathrm{m}$ RML before treatment; (g) after treatment; (h) LSM image of the chip surface, $5 \mu \mathrm{m}$ RML before and (i) after treatment; (j) cross-sectional SEM image of the transformed RML with $5 \mu \mathrm{m}$ thickness.

XRD difractograms are depicted in Figure 5. The parent materials exist in form of fcc $\mathrm{Al}$ (PTC 03-065-2869) and fcc Ni (PTC 03-065-2865) before RTA. (111) Al peak at $2 \theta=38.471^{\circ}$ and (200) $\mathrm{Ni}$ peak at $2 \theta=51.847^{\circ}$ are clearly evident. Between $44^{\circ}<2 \theta<45^{\circ}$, both parent materials and possible formed $\mathrm{Ai} / \mathrm{Ni}$ phases as well have peaks, for that reason these cannot contribute to analysis. After annealing, the (111) Al peaks disappear, and the AlNi phase peaks arise around $2 \theta=31.2^{\circ}$ and 55.5 . Further peaks AlNi are present at $65.023^{\circ}$ and $73.869^{\circ}$. The significant $\mathrm{Al}$ (111) and $\mathrm{Ni}(200)$ peaks are evaluated to assess the parent material presence. Diffractograms of $\mathrm{Al}_{1.1} \mathrm{Ni}_{0.9}$ and $\mathrm{Al}_{0.42} \mathrm{Ni}_{0.58}$ phase are very similar; therefore, they cannot be identified explicitly on the base of the measured XRD data. Consulting the EDX results and considering the fact that fcc Ni is still present after RTA, it can be assumed that $\mathrm{Al}_{1.1} \mathrm{Ni}_{0.9}$ ( $\mathrm{PDF}$ 044-1187) is formed in this process, independently from surface modification and layer thickness. Peaks of fcc Ni were found on all black silicon samples in Figure $5 a$. Its intensity decreases slightly with increasing $\mathrm{T}_{\max }$. This effect can be explained by emerging portions of the Ni-rich $\mathrm{Al}_{0.42} \mathrm{Ni}_{0.58}$ phase, which is formed at higher temperatures. Equally, it decreases on flat wafers with $\mathrm{T}_{\max }$ and here it disappears totally at $\mathrm{T}_{\max }=550{ }^{\circ} \mathrm{C}$, compared with Figure $5 \mathrm{~b}$. Strong Si peaks appear in this measurement due to regions where the reactive layer is peeled off. The samples annealed at $350{ }^{\circ} \mathrm{C}$ show additional peaks, indicating the presence of $\mathrm{Ni} / \mathrm{Si}$ phases. The intensity of the peaks related to $\mathrm{Ni} / \mathrm{Si}$ phases disappear with increasing $\mathrm{T}_{\max }$. 


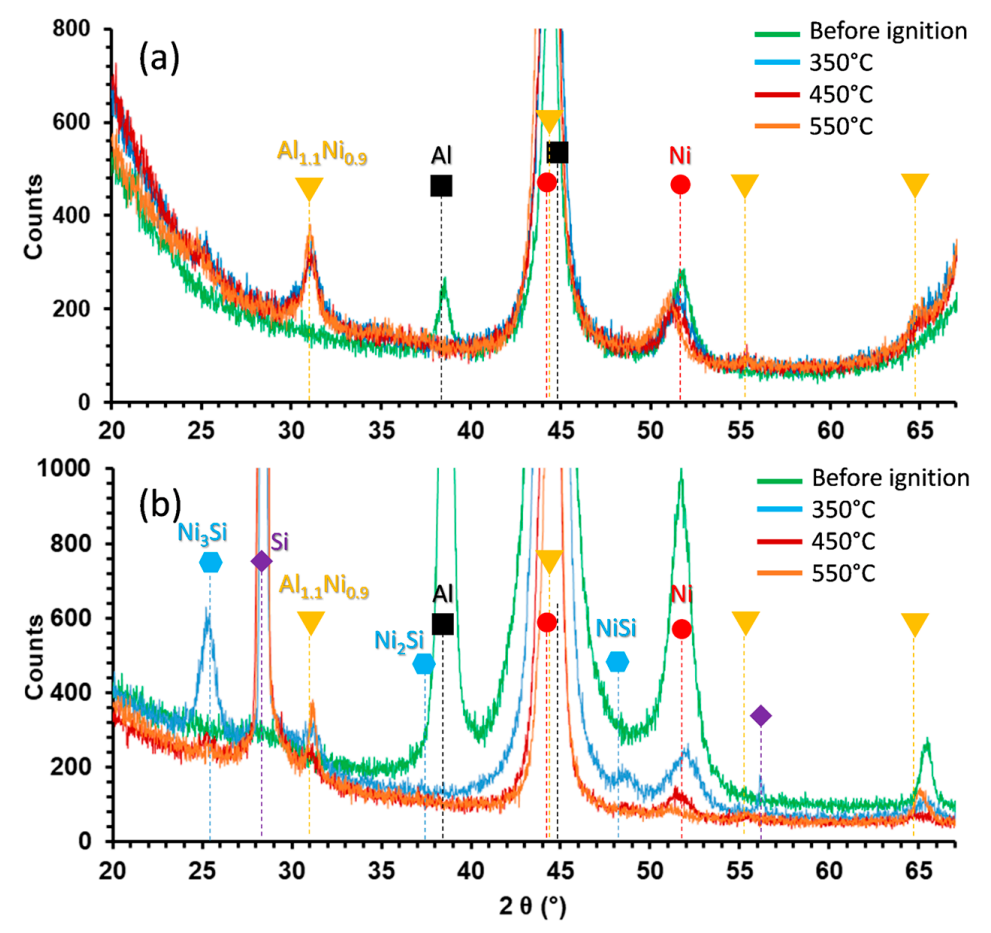

Figure 5. XRD Theta-2Theta curve of RTA treated samples with $1 \mu \mathrm{m}$ RML thickens, (a) on black silicon surface; (b) reference on flat wafer. Identification peaks are associated to PDF 03-065-2869 (fm-3m Al), 03-065-2865 (fm-3m Ni), and 00-044-1187 (pm-3m Al $\mathrm{fl}_{1.1} \mathrm{Ni}_{0.9}$ ).

The intensities of (111) Al peak, (200) Ni peak, and (100) $\mathrm{Al}_{1.1} \mathrm{Ni}_{0.9}$ are used as markers to estimate the relation of present parent material and $\mathrm{Al}_{1.1} \mathrm{Ni}_{0.9}$ phase portions in the mixed crystal. The relative intensity $\mathrm{I}_{\mathrm{relM}}$ of the respective metal is calculated using Equation (1). The index $\mathrm{M}$ is representative of the respective metal: $\mathrm{Al}=$ aluminum, $\mathrm{Ni}=$ nickel and $\mathrm{AlNi}=\mathrm{Al}_{1.1} \mathrm{Ni}_{0.9}$ phase. The intensities $\mathrm{I}_{\mathrm{Al}}, \mathrm{I}_{\mathrm{Ni}}$, and $\mathrm{I}_{\mathrm{NiAl}}$ are extracted from fitted curves of the respective measurement.

$$
\mathrm{I}_{\mathrm{relM}}=\frac{\mathrm{I}_{\mathrm{M}}}{\mathrm{I}_{\mathrm{Al}}+\mathrm{I}_{\mathrm{Ni}}+\mathrm{I}_{\mathrm{AlNi}}} \times 100 \%
$$

The obtained $\mathrm{I}_{\text {relM }}$ for all measurements carried out at $350{ }^{\circ} \mathrm{C}$ are depicted in Figure 6 . Figure 7 compares $\mathrm{I}_{\text {relM }}$ of the $\mathrm{Al}_{1.1} \mathrm{Ni}_{0.9}$ peak for multilayer thickness $1 \mu \mathrm{m}$ and $5 \mu \mathrm{m}$ with the values of $1-\mu \mathrm{m}$-thick multilayer on the flat reference wafer.

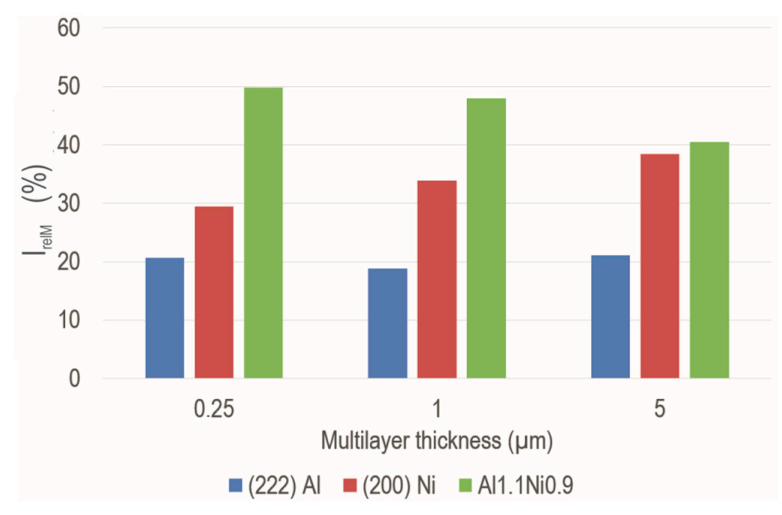

Figure 6. Relation between the intensities of selected peaks as marker for $\mathrm{Al}, \mathrm{Ni}$, and $\mathrm{Al}_{1.1} \mathrm{Ni}_{0.9}$ content after RTA treatment at $350{ }^{\circ} \mathrm{C}$. 


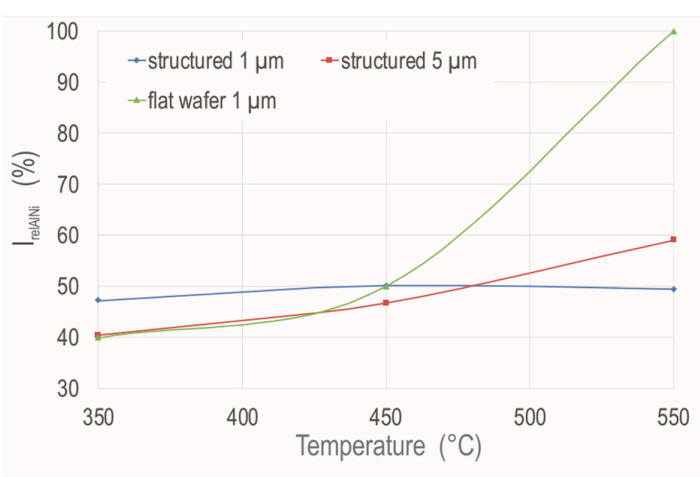

Figure 7. Relative intensity $\mathrm{I}_{\mathrm{AlNi}}$ for total thickness of $1 \mu \mathrm{m}$ and $5 \mu \mathrm{m}$ compared with $1-\mu \mathrm{m}$-thick layer on flat reference wafer.

\section{Discussion}

\subsection{Self-Propagation of the Reaction Front}

Spark ignition creates a local hot spot, which heats a small region and initiates a chain reaction. The propagation depends on amount of heat release and the level of heat losses to the environment. It peters out when the balance of dissipated heat and reaction enthalpy, which is released during the exothermic process, fall below the necessary activation energy. Figure 2 reveals molten areas around the ignition points. Color changes identified by light microscope around the molten region indicate a transition zone of the quenched reaction. The influenced area increases with layer thickness and has a round shape as pointed out in Figure 2a. An irregularity is observed on the samples with $1 \mu \mathrm{m}$ RML thickness. In this case, fused tips peter out astrally, which is visible in the SEM picture in Figure 2b. The self-propagating reaction spreads preferably along the tips of nanostructures with close contact. Figure 8a illustrates the propagation process. The diffusion in thin layers must follow the nanostructure contour, which enlarges the necessary diffusion path. The temperature at the ignition point is high enough that the aluminum can melt and solid-liquid diffusion of $\mathrm{Ni}$ can occur. The fused areas are visible in Figure 2c-d. In parallel, high thermal conductivity of the silicon substrate causes a rapid heat distribution. This can initiate additional solid-solid diffusion if the transformation temperature is reached. This is assumed to be the reason for the formation of the transition zone. Figure 2e depicts this transition zone for 500-nm-thick layer, which spreads over a length of $10 \mu \mathrm{m}$, approximately. It seems that some separated nanostructures are molten form the bottom. The zone observed on $5-\mu \mathrm{m}$-thick layers spans a dimension of $100 \mu \mathrm{m}$. This arises from the circumstance that the larger reactive volume generates a higher heat release whilst heat dissipation conditions remain similar.
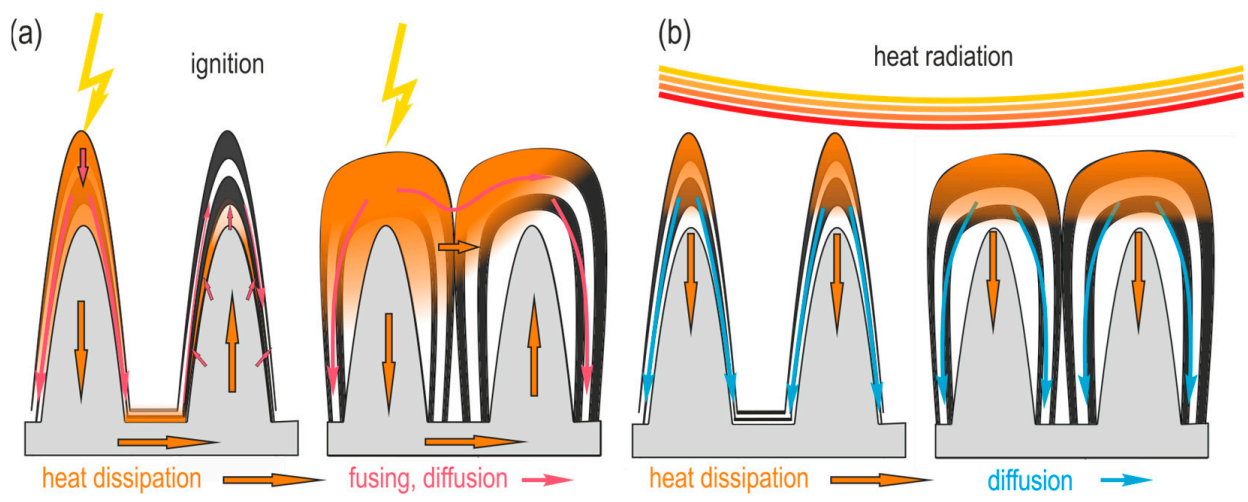

Figure 8. Schematic illustration of the mass and heat transport for thin and thick multilayers. (a) Spark ignition; (b) rapid thermal annealing. 
When the RML becomes thicker, the reaction wave starts to propagate along contact points at the nanostructure tip. When the black silicon is covered with $1 \mu \mathrm{m}$ thick RML layer, some structures come into contact (compare Figure 1d). The propagation along these contact points is the reason for the irregular shape of the molten area occurring at this thickness (Figure $2 b$ ). RML with a thickness of $5 \mu \mathrm{m}$ have a dense contact at the structure tip. This enables fusing along the layer top, enhancing propagation. However, compared to RML deposited on flat surface, the affected radius is smaller indicating that black silicon surface modification hinders the propagation.

The influence of grain boundary defects and the very low thickness of the RML at the foot of black silicon cannot clearly be judged. Some indications can be found in the literature: experiments reveal that stacking faults and defects cause a decrease of the chain reaction efficiency if the bilayer thickness fall below $20 \mathrm{~nm}$ [16]. A reduced cross section of the RML can hinder the propagation of the reaction front and can be used to slow down the velocity $[17,18]$. Molecular dynamic investigations suggest that amorphous aluminum present at grain boundaries promotes the reaction [19]. The observation in the present experiments suggest that the black silicon surface modification hinders the reaction. Detailed investigations on an atomic scale are needed to understand the complex process of combustion waves propagating along curved structures with dimensions in the nanoscale.

\subsection{Rapid Thermal Annealing Tests}

The dominant phase transformation mechanism during RTA is solid-state reaction, no molten areas were observed on the samples. The heat radiation initiates the phase transformation at the nanostructure tips and the transformation propagates perpendicular to the substrate plane, as illustrated in Figure $8 \mathrm{~b}$. Intermetallic phases around the stoichiometric AlNi composition are formed. The $\mathrm{Al}_{1.1} \mathrm{Ni}_{0.9}$ phase contains $42-47$ at $\% \mathrm{Ni}$ [20]. Diffusion studies on Al-Ni-interfaces have shown that the formation of intermetallic phases starts with Al-rich ones [21] as a consequence of the lower melting point of the material. The sputtered parent RML contains stoichiometric composition of $\mathrm{Al}$ and $\mathrm{Ni}$. In RTA treated RML deposited on black silicon, fcc $\mathrm{Ni}$ still is present even at $\mathrm{T}_{\max }$ of $550{ }^{\circ} \mathrm{C}$. The decreasing fcc Ni content with temperature is attributed to emerging Ni-rich intermetallic phase, which requires higher temperatures [22]. The effect occurs similarly on flat samples, but here the excessive fcc $\mathrm{Ni}$ already disappears at lower temperatures. A part of the excessive Ni forms a material bound with the silicon substrate on flat surfaces (see Figure 5b). However, SiNi phases could not be found on the nanostructured samples (Figure 5a). This might be due to the penetration depth of the X-ray measurement, which might hinder the detection of occurring similar phases at the nanostructured interface on the backside of the well adhered layers on these samples. A second possibility is that the nanostructure hinders the phase formation.

The comparison of the relative peak intensity $\mathrm{I}_{\text {relM }}$ in Figure 6 demonstrates that the annealing temperature of $350{ }^{\circ} \mathrm{C}$ is too low to achieve a complete transformation of RML on black silicon. The remaining fcc Ni content increases with increasing RML thickness and fcc Al content remains stable at the same time. This indicates that a complete transformation of the parent materials is not achieved and Al-rich phase is formed preferably. The incompleteness of the transformation increases with layer thickness, indicating that the annealing temperature of $350{ }^{\circ} \mathrm{C}$ is too low to initiate an exothermic chain reaction, because otherwise the released energy would foster a transformation. An increase of the temperature up to $550^{\circ} \mathrm{C}$ (Figure 7) also fails to lead to a complete transformation. In comparison to this, 1- $\mu \mathrm{m}$-thick RML can be completely transformed at $\mathrm{T}_{\max } 550^{\circ} \mathrm{C}$ if they are applied on flat silicon. It can therefore be concluded that the nanostructured surface hinders the transformation.

\section{Conclusions}

Reactive $\mathrm{Al} / \mathrm{Ni}$ multilayers were deposited on nanostructured black silicon and pristine flat silicon wafer for comparison purpose. The black silicon interface disturbs the morphology of the parent AlNi multilayer, in particular at the foot of the nanostructure. In comparison with the flat surface, black silicon hinders the self-propagating reaction initiated by electric spark. The solid-state 
reaction initiated by rapid thermal annealing could not fully transform the parent materials on black silicon, whilst it was achieved for flat surfaces at a maximum temperature $550{ }^{\circ} \mathrm{C}$. The reaction is hindered by the nanostructure as well. This behavior can help to control the reaction dynamics and it can be used to control the reaction propagation when the RML is used for chip assembly on heat sinks. The presence of almost stoichiometric AlNi phases leads to the conclusion, that high temperatures have been achieved. Thus, the use of RML on black silicon as local heat source for soldering processes with restricted heat-affected zone is possible.

The significantly enhanced adhesion of the RML on black silicon in comparison with the pristine wafer surface promises an additional improvement of the reliability of the thermal interface. Further studies must investigate stress, considering different chip assembly scenarios.

Since nanostructure influences the microstructure of the parent material, reaction propagation, and interface morphology, precise studies of single effects are necessary. As an optimum approach to understand this complex process, a combination of molecular dynamic simulations and experimental work will be the focus of following studies.

Acknowledgments: The authors acknowledge for the support from the Alexander von Humboldt Foundation, through the "Humboldt Research Fellowship for Postdoctoral Researchers Program" (Ref. 3.3-1 1S8421-ES-HFST-P). A special thank goes to Jens Müller for supervising this exchange. Furthermore, the authors would express deep thankfulness to Peter Schaaf who enabled the sound cooperation among all staff of the material science department of IMN MacroNano ${ }^{\circledR}$ and the authors as base for this study.

Author Contributions: Heike Bartsch designed the experiments, performed the experiments, interpreted the results and wrote the paper. José Manuel Mánuel performed SEM and TEM studies, carried out XRD measurements and analyzed the respective data. Rolf Grieseler conceived the experiment and provided his experience of reactive multilayer processing and analysis. He supported the methodology concept and discussion section.

Conflicts of Interest: The authors declare no conflict of interest.

\section{References}

1. Grace O'Malley. Highlights from the iNEMI Thermal Management Technology Roadmap, Advancing in Manufacturing Technology. 2014. Available online: http://thor.inemi.org/webdownload/2014/Eurotherm_ 061914.pdf (accessed on 4 December 2017).

2. Yeh, L.-T. Thermal Management/Roadmap and Energy Efficiency for Telecommunications Equipment. J. Comput. Intel. Electron. Syst. 2015, 4, 1-9. [CrossRef]

3. Mahajan, R.; Chiu, C.-P.; Prasher, R.S. Thermal Interface Materials: A Brief Review of Design Characteristics and Materials. Electron. Cool. 2004, 10, 10-18.

4. Welker, T.; Geiling, T.; Bartsch, H.; Müller, J. Design and Fabrication of Transparent and Gas-Tight Optical Windows in Low-Temperature Co-Fired Ceramics. Int. J. Appl. Ceram. Technol. 2013, 10, 405-412. [CrossRef]

5. Subramanian, J.; Rodgers, P.; Newson, J.; Rude, T.R.; He, Z.; Besnoin, E.; Weihs, T.; Eveloy, V.; Pecht, M. Room Temperature Soldering of Microelectronic Components for Enhanced Performance. In Proceedings of the IEEE International Conference on Thermal, Mechanical and Multiphysics Simulation and Experience in Microelectronics and Microsystems, Berlin, Germany, 18-20 April 2006; pp. 681-686.

6. Bräuer, J.; Besser, J.; Wiemer, M.; Gessner, T. A novel technique for MEMS packaging: Reactive bonding with integrated material systems. Sens. Actuators A Phys. 2012, 188, 212-219. [CrossRef]

7. Bräuer, J.; Gessner, T. A hermetic and room-temperature wafer bonding technique based on integrated reactive multilayer systems. J. Micromech. Microeng. 2014, 24, 115002. [CrossRef]

8. Grieseler, R.; Welker, T.; Müller, J.; Schaaf, P. Bonding of low temperature co-fired ceramics to copper and to ceramic blocks by reactive aluminum/nickel multilayers. Phys. Status Solidi A 2012, 209, 512-518. [CrossRef]

9. Miyake, S.; Kanetsuki, S.; Morino, K.; Kuroishi, J.; Namazu, T. Thermal property measurement of solder joints fabricated by self-propagating exothermic reaction in $\mathrm{Al} / \mathrm{Ni}$ multilayer film. Jpn. J. Appl. Phys. 2015, 54, 06FP15. [CrossRef]

10. Namazu, T.; Ohtani, K.; Inoue, S.; Miyake, S. Influences of Exothermic Reactive Layer and Metal Interlayer on Fracture Behavior of Reactively Bonded Solder Joints. J. Eng. Mater. Technol. 2015, 137, 031011. [CrossRef] 
11. Bar-Cohen, A.; Matin, K.; Narumanchi, S. Nanothermal Interface Materials: Technology Review and Recent Results. J. Electron. Packag. 2015, 137, 040803. [CrossRef]

12. Feng, B.; Cao, J.; Wang, Y.; Feng, J. Enhanced Adhesive Bonding Based on Surface Modification with Silicon Nanowire Arrays. ECS J. Solid State Sci. Technol. 2015, 5, P41-P46. [CrossRef]

13. Fischer, M.; Bartsch, H.; Pawlowski, B.; Gade, R.; Barth, S.; Mach, M.; Stubenrauch, M.; Hoffmann, M.; Müller, J. Silicon on Ceramics-A New Integration Concept for Silicon Devices to LTCC. J. Microelectron. Electron. Packag. 2009, 1, 1-5. [CrossRef]

14. Jansen, H.V.; de Boer, M.J.; Unnikrishnan, S.; Louwerse, M.C.; Elwenspoek, M.C. Black silicon method X: A review on high speed and selective plasma etching of silicon with profile control: An in-depth comparison between Bosch and cryostat DRIE processes as a roadmap to next generation equipment. J. Micromech. Microeng. 2009, 19, 033001. [CrossRef]

15. Pezoldt, J.; Kups, T.; Stubenrauch, M.; Fischer, M. Black luminescent silicon. Phys. Status Solidi C 2011, 8, 1021-1026. [CrossRef]

16. Theodossiadis, G.D.; Zaeh, M.F. Study of the kinetic and energetic reaction properties of multilayered aluminum-nickel nanofoils. Prod. Eng. Res. Devel. 2017, 11, 245-253. [CrossRef]

17. Sraj, I.; Vohra, M.; Alawieh, L.; Weihs, T.P.; Knio, O.M. Self-Propagating Reactive Fronts in Compacts of Multilayered Particles. J. Nanomater. 2013, 2013, 1-11. [CrossRef]

18. Fritz, G.M.; Joress, H.; Weihs, T. Enabling and controlling slow reaction velocities in low-density compacts of multilayer reactive particle. Combust. Flame 2011, 158, 1084-1088. [CrossRef]

19. Politano, O.; Baras, F.; Mukasyan, A.S.; Vadchenko, S.G.; Rogachev, A.S. Microstructure development during $\mathrm{NiAl}$ intermetallic synthesis in reactive Ni-Al nanolayers: Numerical investigations vs. TEM observations. Surf. Coat. Technol. 2013, 215, 485-492. [CrossRef]

20. Urrutia, A.; Tumminello, S.; Aricó, S.F.; Sommadossi, S. Characterization of Al-Ni intermetallics around 30-60 at \% Al for TLPB application. CALPHAD Comput. Coupl. Phase Diagr. Thermochem. 2014, 44, 108-113. [CrossRef]

21. Tumminello, S.; Sommadossi, S. Growth Kinetics of Intermetallic Phases in Transient Liquid Phase Bonding Process (TLPB) in Al/Ni System. Defect Diffus. Forum 2012, 323-325, 465-470. [CrossRef]

22. Urrutia, A.; Tumminello, S.; Lamas, D.G.; Sommadossi, S. X-Ray Characterization of Intermetallic Phases in Al/Ni Multilayer System. Proced. Mater. Sci. 2015, 8, 1150-1159. [CrossRef] 